\title{
Java Red Rice (Oryza sativa L.) Nutritional Value and Anthocyanin Profiles and Its Potential Role as Antioxidant and Anti-Diabetic
}

\author{
Ayu Tri Agustin ${ }^{1,2}$, Anna Safitri ${ }^{2,3}$, and Fatchiyah Fatchiyah ${ }^{1,2^{*}}$ \\ ${ }^{1}$ Department of Biology, Faculty of Mathematics and Natural Sciences, Brawijaya University, \\ Jl. Veteran, Malang 65145, East Java, Indonesia \\ ${ }^{2}$ Research Center of Smart Molecule of Natural Genetics Resource, Brawijaya University, Malang 65145, East Java, Indonesia \\ ${ }^{3}$ Department of Chemistry, Faculty of Mathematics and Natural Sciences, Brawijaya University, \\ Jl. Veteran, Malang 65145, East Java, Indonesia
}

* Corresponding author:

tel: $+62-341-575-841$

email:fatchiya@ub.ac.id

Received: March 5, 2021

Accepted: April 20, 2021

DOI: $10.22146 /$ ijc. 64509

\begin{abstract}
This study investigates nutritional value, amino acid profile, and total anthocyanin in pigmented rice as an antioxidant and anti-diabetic agent. Six rice varieties were extracted using $0.1 \% \mathrm{HCl}$ in methanol, namely four red rice, one black rice, and one white rice. Rice extract was used for proximate analysis and amino acid profiling. Total anthocyanin was measured and identified by ultraviolet-visible (UV-Vis) spectrophotometer and thin-layer chromatography (TLC). The antioxidant activity was determined using Ferric-reducing antioxidant power (FRAP) assay, and the $\alpha$-amylase enzyme-inhibited by anthocyanin extract of red rice as anti-diabetic was measured. The study result showed that the proximate level (carbohydrate, protein, lipid, water, and ash) in pigmented rice was different. Cempo merah red rice is a source of amino acids, both essential and non-essential amino acids that act as good nutrition. The highest total anthocyanin level between red rice varieties of $10.87 \mathrm{mg} / \mathrm{g}$ was found in Aek sibundong red rice. High biological function activities as an antioxidant were indicated by Aek sibundong red rice with an $I C_{50}$ value of $6.65 \mu \mathrm{g} / \mathrm{mL}$. Aek sibundong red rice shows the lowest $I C_{50}$ value of $144.46 \mu \mathrm{g} / \mathrm{mL}$ in anti-diabetic activity. Thus, Aek sibundong red rice may have the potential as $\alpha$-amylase inhibitor for diabetes prevention.
\end{abstract}

Keywords: anthocyanin; bioactivity; nutrition; pigmented rice

\section{- INTRODUCTION}

Rice (Oryza spp.) consists of 40,000 varieties worldwide and is divided into two widely cultivated types, namely Oryza sativa (Asian rice) and Oryza glaberrima (African rice) [1]. Based on the pericarp color, rice is divided into several cultivars, including white, red, black, and purple rice. It is determined by the accumulation of proanthocyanidin and anthocyanin pigments in the pericarp, seed coat, and aleurone [2]. Various bioactive compounds in pigmented rice are beneficial for the health and prevention of metabolic diseases [3]. Generally, red rice is rich in nutrients such as calcium, zinc, magnesium, protein, and fiber compared to white rice [4]. Proximate analysis shows that the vitamin $\mathrm{B} 1$ content of red rice is higher than black rice [5]. The main phytochemical content of red rice includes phenolics, flavonoids, proanthocyanidins, and anthocyanins. It has biological functions to reduce free radicals, oxidative stress and prevent lipid peroxidation [6].

The dominant phenolic compounds found in red rice varieties include ferulic, vanillic, and protocatechuic acid [7]. Research by Thitipramote et al. [8] shows that ethanol extract from Brown Red Jasmine (BRJ) red rice contains phenolic compounds and the highest antioxidant activity among Kam Leum Pua (KLP) black rice and Japanese Brown Rice (JBR) white rice. This high antioxidant activity is supported by the presence of proanthocyanidins found only in BRJ red rice. Effective extraction and identification methods are 
essential in anthocyanin analysis. Using $0.1 \% \mathrm{HCl}$ in methanol is an optimum solvent for anthocyanin extraction of rice [9]. The addition of hydrochloric acid is needed to increase solvent polarity and maintain anthocyanin stability [10]. Anthocyanin identification is commonly performed using a spectrophotometric approach based on changes in the structure and absorption of anthocyanins at different $\mathrm{pHs}$ (generally $\mathrm{pH}$ 1.0 and $\mathrm{pH} 4.5$ ). It is referred to as a $\mathrm{pH}$ differentiation method [11]. The thin-layer chromatography (TLC) method was carried out to identify anthocyanins and organic compounds in pigmented rice [12].

Anthocyanins consist of a benzoyl ring [A], a pyran ring $[\mathrm{C}]$, and a phenolic ring $[\mathrm{B}]$, as well as a sugar group at position $\mathrm{C} 3$ in the heterocyclic $[\mathrm{C}]$ ring. These sugar groups include glucose, galactose, xylose, rhamnose, and arabinose. The addition of sugar groups (glycosylation) may increase the anthocyanin stability in water. Anthocyanins commonly found in plants include pelargonidin, peonidin, cyanidin, malvidin, petunidin, and delphinidin [13]. The chemical structure of anthocyanins, such as the position and number of hydroxyl groups or methoxy group as electron donors, has a strong effect on antioxidant activity [14]. Biological function test of cyanidin-3-O-glucoside in red rice showed inhibition of Advanced Glycation End-products (AGEs)-Receptor for AGEs (RAGE), which is involved in the chronic inflammatory cascade, diabetes, and its complications [15]. Peonidin-3-O-glucoside can inhibit the tumor necrosis factor alpha (TNF- $\alpha$ ) signaling pathway so that it has the potential to be antiinflammatory [16]. A previous study reported that brown rice extract consumed by hyperglycemic rats induced using streptozotocin (STZ) and nicotinamide (NA) could reduce blood glucose up to $50.9 \%$ [17]. In vivo study on dyslipidemia mice treated with anthocyanin from pigmented rice showed decreased cholesterol levels, malondialdehyde (MDA), and the expression of genes involved in obesity [18]. The inhibitory activities of $\alpha$ amylase and $\alpha$-glucosidase were carried out on red, purple, and brown rice bran extracts to evaluate their antidiabetic effect in vitro. Among other pigmented rice, red rice bran was able to inhibit the enzymes $a$-amylase
(46.2\%) and a-glucosidase (reaching 91.8\%) [19]. The potential role of whole grain extracts of red rice in inhibiting glucose digestion enzymes has limited information. The $a$-amylase enzyme is secreted by the salivary glands and pancreas, which can break the internal bonds of $\alpha$-1,4-starch glycosides to produce maltose and glucose. When the $\alpha$-amylase enzyme is inhibited, it will slow down the digestion of carbohydrates [20]. Thus, the glucose absorption rate into the blood will decrease.

Besides genetic factors, the growing environment, such as light, temperature, drought, and soil salinity, can affect variations in the content of bioactive compounds in red rice [21]. In Indonesia, red rice is divided into more than 60 varieties spread across Java, Bali, Sumatra, Sulawesi, and NTT. Research related to physicochemical characterization and antioxidant activity has been carried out on two local red rice varieties of North Buton, Wakawondu, and Wangkakiri varieties [22]. In the current study, four local Javanese red rice varieties were used. Blambangan and Aek sibundong red rice varieties were obtained from East Java, while red rice varieties of Cempo Merah and Inpari 24 were obtained from Central Java. Mentik susu white rice and wojalaka black rice were obtained from East Java as control. We aimed to investigate nutritional value, amino acid profile, total anthocyanin, and antioxidant and antidiabetic activity in six pigmented rice varieties.

\section{- EXPERIMENTAL SECTION}

\section{Materials}

The chemicals used were $1.0 \mathrm{M} \mathrm{HCl}$, methanol $(\mathrm{MeOH}$ 99.9\%), a-aminobutyric acid (AABA), $\alpha-$ amylase enzyme (334 units/mg from Aspergillus oryzae), AccQ•Fluor Borate, fluorine reagent A, potassium chloride buffer, n-butanol, acetic acid, phosphate buffer, potassium ferricyanide, Trichloroacetic Acid (TCA) $10 \%$, ferric chloride, and dinitrosalicylic acid reagent. In addition, various rice varieties were used, including Mentik Susu white rice (WREJms) as a negative control, Wojalaka black rice (BREJwj) as a positive control, Cempo Merah red rice (RRCJcm), Blambangan red rice 
(RREJbl), Inpari 24 red rice (RRCJin), and Aek Sibundong red rice (RREJas) (Fig. 1).

\section{Instrumentation}

Anthocyanin extraction was optimized using a shaking water bath at $25{ }^{\circ} \mathrm{C}$. Solvent evaporation was performed using a rotary evaporator. The instrument used to determine the proximate components were Kjeltec $^{\mathrm{TM}}$ and Soxhlet. The amino acid was determined Ultra-Performance Liquid Chromatography (UPLC), Liquid Chromatography-Mass Spectrometry (LC-MS), and High-Performance Liquid Chromatography (HPLC). $\mathrm{UV}$-Vis spectrophotometer was employed to measure the absorbance of the extract. The identification of anthocyanin compounds was carried out on a silica gel plate $\mathrm{F}_{254}$ and visualized under a UV chamber.

\section{Procedure}

\section{Extraction of anthocyanin from pigmented rice}

Extraction was carried out using the maceration method. The $250 \mathrm{~g}$ of sample powder was dissolved with $1000 \mathrm{~mL}$ of $0.1 \% \mathrm{HCl}$ in methanol [9]. Total extracts were then incubated in a shaking water bath at $25^{\circ} \mathrm{C}$ overnight. The filtrate was obtained using a $0.45 \mu \mathrm{m}$ Whatman filter

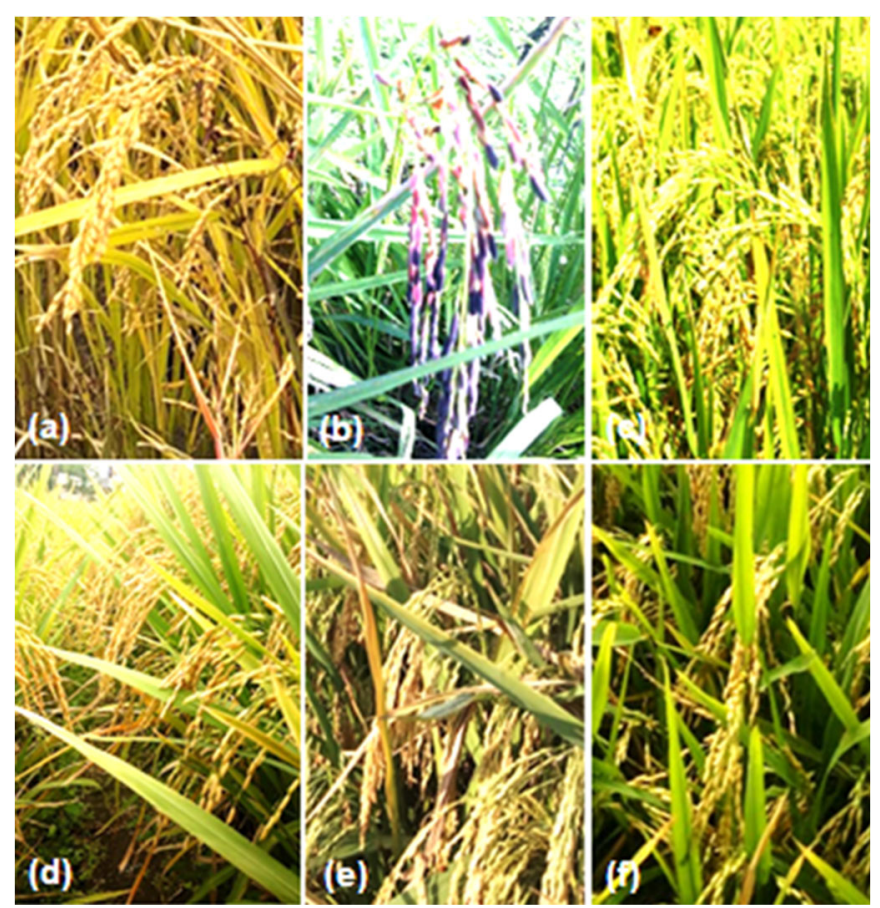

Fig 1. Various pigmented rice. (a) WREJms, (b) BREJwj, (c) RRCJcm, (d) RREJbl, (e) RRCJin, and (f) RREJas paper and then concentrated in a rotary evaporator. The evaporated extract was stored at $4^{\circ} \mathrm{C}$ for further analysis.

\section{Proximate analysis}

Proximate analysis for carbohydrates was carried out according to the standard 18-8-9/MU/SMM-SIG protocol, protein according to the 18-8-31/MU/SMMSIG (Kjeltec), lipid according to the 18-8-5/MU/SMMSIG (Soxhlet), water and ash content according to the Indonesian National Standard (SNI 6128:2015 and SNI 01-2891:1992).

\section{Amino acid determination}

Characterization of essential and non-essential amino acid profiles was carried out using the Ultra Performance Liquid Chromatography (UPLC) method [23]. Briefly, $0.1 \mathrm{~g}$ of pigmented rice were dissolved in $5 \mathrm{~mL}$ of $6 \mathrm{~N} \mathrm{HCl}$. Then, each solution was vortexed and heated at $110{ }^{\circ} \mathrm{C}$. Distilled water was added to the solution until the final solution volume was $50 \mathrm{~mL}$. The resulted solution was filtered and dissolved in $40 \mu \mathrm{m}$ AABA and $460 \mu \mathrm{L}$ distilled water. A $10 \mu \mathrm{L}$ of the solution was added to the $70 \mu \mathrm{L}$ of AccQ-Fluor Borate and vortexed. Then, $20 \mu \mathrm{L}$ of fluorine reagent $\mathrm{A}$ was added to the solution and was incubated at $55^{\circ} \mathrm{C}$ for $10 \mathrm{~min}$. After incubation, the solution was injected onto the UPLC column (AccQ.Tag Ultra C18 $1.7 \mu \mathrm{m}$ ) according to the 8-5-17/MU/SMM protocol-SIG (UPLC), 18-1238/MU/SMM-SIG (LC-MS/MS) for the amino acids LCystine and L-Methionine test, and 18-5-63/MU/SMMSIG (HPLC) for the amino acid L-Tryptophan test.

\section{Determination of total anthocyanin content}

Anthocyanin content in the sample extract was determined based on the $\mathrm{pH}$ differentiation method [24]. A $0.1 \mathrm{~g}$ of the paste extract was dissolved in $2 \mathrm{~mL}$ of potassium chloride buffer $\mathrm{pH} 1.0$ and $\mathrm{pH} 4.5$ separately. Each solution was vortexed, filtered, and centrifuged at $2500 \mathrm{rpm}$ at $25^{\circ} \mathrm{C}$ for $10 \mathrm{~min}$. Buffer solution $\mathrm{pH} 1.0$ and $\mathrm{pH} 4.5$ were used as blank solutions. The absorbance was measured at 200-800 $\mathrm{nm}$ using a UV-Vis spectrophotometer. Total anthocyanin content was calculated as follows:

Anthocyanin content $(\mathrm{mg} / \mathrm{g})=\frac{\mathrm{A} \times \mathrm{MW} \times \mathrm{DF} \times 1000}{\mathrm{MA} \times 1}$ 
with:

A: The formula determines the absorbance of the sample: $A=\left(A_{\lambda V i s-m a x ~ n m}-A_{700 ~ n m}\right)_{\mathrm{pH} 1.0}-\left(A_{\lambda V i s-m a x ~ n m}-A_{700} \mathrm{~nm}\right)_{\mathrm{pH}} 4.5$ MW: Molecular weight of cyanidin-3-O-glucoside (449.2 $\mathrm{g} / \mathrm{mol}$ )

DF: Dilution factor

MA: Molar absorbtivity of cyanidin-3-O-glucoside

\section{Thin layer chromatography (TLC) analysis}

Concisely, $0.1 \mathrm{~g}$ paste extract was diluted with $0.4 \mathrm{~mL}$ $0.1 \% \mathrm{HCl}$ in methanol. The solution was vortexed, then centrifuged at $2500 \mathrm{rpm}$ at $25^{\circ} \mathrm{C}$ for $10 \mathrm{~min} .0 .3 \mathrm{mg} / \mathrm{mL}$ of supernatant was spotted on the silica gel plate $\mathrm{F}_{254}$. Next, the silica gel plate $\mathrm{F}_{254}$ that had been spotted was eluted in the mobile phase with eluent $n$-butanol:acetic acid:distilled water (3:1:1). The spots were observed under UV chamber of $254 \mathrm{~nm}$ and $366 \mathrm{~nm}$, then the intensity and density of each spot were determined using ImageJ software, and the retention factor (Rf) was measured [18].

\section{Antioxidant activity assay}

Samples were diluted with $0.1 \% \mathrm{HCl}$ in methanol with concentrations of $0,2,4,6,8,10 \mu \mathrm{g} / \mathrm{mL}$. The solution was mixed with $200 \mathrm{mmol} / \mathrm{L}$ phosphate buffer $(2.5 \mathrm{~mL})$ $\mathrm{pH} 6.6$ and $1 \%$ potassium ferricyanide $2.5 \mathrm{~mL}$. The solution was incubated at $50{ }^{\circ} \mathrm{C}$ for $30 \mathrm{~min}$, then $2.5 \mathrm{~mL}$ of $10 \%$ TCA was added. An aliquot of the solution $(5 \mathrm{~mL})$ was transferred to a new test tube. Lastly, $5 \mathrm{~mL}$ of distilled water and $0.1 \%$ ferric chloride $1 \mathrm{~mL}$ were added to each tube. The absorbance was measured at $700 \mathrm{~nm}$ using a UV-Vis spectrophotometer. The antioxidant activity was calculated as follows: Percentage of antioxidant = $\{[($ absorbance of control - absorbance of sample)/ absorbance of control] $\times 100\}$. The $\mathrm{IC}_{50}$ value was determined using a linear regression equation ( $x$ and $y$ axes, respectively) of extract concentration and its antioxidant activity [25].

\section{a-Amilase enzyme inhibitory activity}

Briefly, $250 \mu \mathrm{L}$ of pigmented rice extracts (10$100 \mu \mathrm{g} / \mathrm{mL}$ ), buffer control and positive control (the acarbose $1-10 \mu \mathrm{g} / \mathrm{mL}$ ) were added with $250 \mu \mathrm{L}$ of $\alpha$ amylase enzyme (334 units/mg from Aspergillus oryzae). Each solution was incubated at $37^{\circ} \mathrm{C}$ for $30 \mathrm{~min}$. Next, amylum $1 \%$ was added to each tube and incubated at $25^{\circ} \mathrm{C}$ for $10 \mathrm{~min}$. Then, $500 \mu \mathrm{L}$ of dinitrosalicylic acid reagent was added and incubated in boiling water for $5 \mathrm{~min}$. Lastly, each solution was added $5 \mathrm{~mL}$ of distilled water. The absorbance was measured at $495 \mathrm{~nm}$, and the $\mathrm{IC}_{50}$ value was determined. The inhibitory activity of $\alpha$ amylase was determined by the percentage of enzyme inhibition against the extract [26].

\section{Data analysis}

One-way Analysis of Variance (ANOVA) and Brown-Forsythe using SPSS Statistic v16 software performed statistical analysis of TAC, intensity, and density. The statistically significant test was determined at $\mathrm{p}<0.05$ [27]. Results were expressed as mean \pm standard deviation (SD) of triplicate experiments.

\section{- RESULTS AND DISCUSSION}

\section{Nutritional Value and Amino Acid Residue of Pigmented Rice}

The nutrition component of pigmented rice was determined by proximate analysis, while the amino acid residues were determined by the UPLC method. Evidence of macro and micronutrient components is very important in the development of functional foods. Pigmented rice is a staple food rich in macronutrients such as carbohydrates, fiber, protein, and fat as an energy source [28]. These studies showed that carbohydrate, protein, lipid, ash, and moisture content among pigmented rice have different values (Table 1). Several factors influence pigmented rice macronutrients variation, including genetic factors, environment, rice milling, and storage [5]. The percentage of carbohydrates in red rice varieties was $71.07 \%-74.49 \%$. In the human body, carbohydrates are hydrolyzed into monosaccharides, disaccharides, starch, and other smaller components. A high carbohydrate diet can trigger hyperglycemia [5]. However, RREJbl red rice has the lowest carbohydrate content. RRCJcm red rice has a protein content of $11.23 \%$, higher than BREJwj black rice, which has a protein content of $10.14 \%$. The fat level in red rice is around $4.34 \%-5.81 \%$, whereas the lowest level was RREJas red rice. The previous studies also found similar variations in the nutritional value of rice $[5,7]$. 
Table 1. Profile of nutrition and amino acid residues composition in pigmented rice

\begin{tabular}{|c|c|c|c|c|c|c|}
\hline (a) Constituents & WREJms & BREJwj & $\mathrm{RRCJ} \mathrm{cm}$ & RREJbl & RRCJin & RREJas \\
\hline Carbohydrate (\%) & $75.125 \pm 0.05^{*}$ & $72.92 \pm 0.07$ & $71.94 \pm 0.14$ & $71.065 \pm 0.045$ & $72.79 \pm 0.02$ & $74.49 \pm 0.05$ \\
\hline Protein $(\%)$ & $11.82 \pm 0.01^{*}$ & $10.135 \pm 0.045$ & $11.225 \pm 0.095$ & $10.985 \pm 0.055$ & $9.445 \pm 0.145$ & $10.82 \pm 0.06$ \\
\hline Lipid (\%) & $1.16 \pm 0.02$ & $4.775 \pm 0.065$ & $5.805 \pm 0.035^{\star}$ & $5.59 \pm 0.08$ & $5.25 \pm 0.07$ & $4.34 \pm 0.03$ \\
\hline Moisture content (\%) & $10.97 \pm 0.05^{\star}$ & $9.515 \pm 0.055$ & $8.655 \pm 0.055$ & $9.495 \pm 0.055$ & $9.925 \pm 0.055^{\star}$ & $7.88 \pm 0.05$ \\
\hline $\operatorname{Ash}(\%)$ & $0.925 \pm 0.025$ & $2.655 \pm 0.035$ & $2.375 \pm 0.025$ & $2.865 \pm 0.035^{\star}$ & $2.59 \pm 0.04$ & $2.47 \pm 0.03$ \\
\hline $\begin{array}{l}\text { (b) Amino acid } \\
(\mathrm{mg} / \mathrm{Kg})\end{array}$ & WREJms & BREJwj & $\mathrm{RRCJ} \mathrm{cm}$ & RREJbl & RRCJin & RREJas \\
\hline \multicolumn{7}{|l|}{ Essential amino acids } \\
\hline L-Phenylalanine & $7041.50 \pm 13.20$ & $5671.60 \pm 1.93$ & $7194.08 \pm 9.41^{\star}$ & $6649.84 \pm 18.33$ & $4876.60 \pm 4.54$ & $5218.72 \pm 13.43$ \\
\hline L-Isoleucine & $4394.41 \pm 1.22$ & $4066.33 \pm 15.06$ & $4501.66 \pm 18.31^{\star}$ & $4316.34 \pm 1.64$ & $4043.50 \pm 9.95$ & $4083.41 \pm 9.63$ \\
\hline L-Valine & $6652.15 \pm 51.83$ & $6430.91 \pm 10.33$ & $6888.28 \pm 24.79^{*}$ & $6589.49 \pm 24.40$ & $6159.63 \pm 5.27$ & $6054.40 \pm 36.77$ \\
\hline L-Lysine & $4256.26 \pm 10.72^{\star}$ & $4084.85 \pm 8.54$ & $3923.48 \pm 23.08$ & $3907.21 \pm 4.08$ & $3763.41 \pm 4.04$ & $4223.05 \pm 18.32^{\star}$ \\
\hline L-Leucine & $8718.39 \pm 39.35$ & $7959.40 \pm 13.30$ & $8911.00 \pm 11.36^{\star}$ & $8558.51 \pm 2.16$ & $8024.24 \pm 1.54$ & $8105.08 \pm 28.82$ \\
\hline L-Threonine & $4872.74 \pm 8.76$ & $4661.00 \pm 19.63$ & $5386.79 \pm 5.26^{*}$ & $5101.63 \pm 9.89$ & $4425.68 \pm 13.10$ & $4406.68 \pm 19.84$ \\
\hline L-Histidine & $2995.33 \pm 12.11$ & $2953.04 \pm 8.95$ & $3711.28 \pm 7.43^{\star}$ & $3405.98 \pm 17.43$ & $2667.81 \pm 5.68$ & $2608.70 \pm 16.77$ \\
\hline L-Methionine & $2466.04 \pm 1.23^{\star}$ & $2027.91 \pm 1.80$ & $2422.98 \pm 0.71$ & $2249.76 \pm 1.12$ & $1844.37 \pm 0.92$ & $2260.31 \pm 0.90$ \\
\hline L-Tryptophan & $1550.67 \pm 0.99^{\star}$ & $1181.33 \pm 0.67$ & $1209.88 \pm 5.79$ & $1229.28 \pm 5.43$ & $1209.24 \pm 5.33$ & $1188.82 \pm 0.34$ \\
\hline \multicolumn{7}{|l|}{ Non-essentials } \\
\hline L-Serine & $7676.81 \pm 57.02^{*}$ & $5755.88 \pm 7.96$ & $7530.38 \pm 14.29$ & $6432.35 \pm 7.12$ & \multicolumn{2}{|c|}{$5708.48 \pm 17.526247 .60 \pm 44.45$} \\
\hline L-Glutamic acid & $19756.37 \pm 111.22^{*}$ & $18454.93 \pm 35.82$ & $18685.57 \pm 69.31$ & $16815.84 \pm 72.20$ & \multicolumn{2}{|c|}{$15346.26 \pm 38.6118655 .68 \pm 123.59$} \\
\hline L-Aspartic acid & $8922.30 \pm 42.33$ & $9282.61 \pm 12.65$ & $9383.25 \pm 28.80^{*}$ & $7680.57 \pm 21.63$ & \multicolumn{2}{|c|}{$7208.30 \pm 4.868955 .61 \pm 33.66$} \\
\hline L-Tyrosine & $4791.15 \pm 23.06$ & $3604.19 \pm 2.53$ & $5083.72 \pm 16.72^{\star}$ & $4398.77 \pm 0.05$ & \multicolumn{2}{|c|}{$3272.53 \pm 4.243723 .00 \pm 23.86$} \\
\hline L-Proline & $4683.12 \pm 13.91$ & $4491.93 \pm 47.98$ & $4693.33 \pm 13.10^{*}$ & $4496.24 \pm 2.01$ & \multicolumn{2}{|c|}{$4160.27 \pm 13.654384 .31 \pm 9.58$} \\
\hline L-Alanine & $5995.01 \pm 39.74$ & $6028.48 \pm 23.82$ & $6297.38 \pm 37.89^{*}$ & $5706.91 \pm 29.03$ & \multicolumn{2}{|c|}{$5343.24 \pm 17.546033 .32 \pm 18.11$} \\
\hline L-Arginine & $9393.25 \pm 11.01$ & $8480.83 \pm 89.45$ & $9596.37 \pm 54.24^{*}$ & $8707.33 \pm 33.22$ & \multicolumn{2}{|c|}{$7361.11 \pm 22.377690 .07 \pm 27.88$} \\
\hline Glycine & $5202.28 \pm 26.17$ & $4942.58 \pm 11.75$ & $5932.36 \pm 23.87^{\star}$ & $5488.05 \pm 19.18$ & \multicolumn{2}{|c|}{$5050.48 \pm 8.694829 .40 \pm 22.53$} \\
\hline L-Cysteine & $2561.51 \pm 1.28$ & $1970.56 \pm 0.88$ & $2422.74 \pm 2.45$ & $2615.46 \pm 2.18^{*}$ & \multicolumn{2}{|c|}{$1651.06 \pm 0.822346 .79 \pm 0.93$} \\
\hline
\end{tabular}

Note: An asterisk $\left.{ }^{*}\right)$ show the highest value with $5 \%$ probability $(\mathrm{P}<0.05)$

Generally, amino acids are classified into essential amino acids and non-essential amino acids. Non-essential amino acids can be synthesized in the body to promote optimal growth and health. Essential amino acids cannot be synthesized in the body but derived from foods [29]. Glutamic acid is the non-essential amino acid most predominantly found in all rice (Table 1(b)). These findings are similar to previous studies, where glutamic acid was dominated in black rice, red rice, and white rice [18]. Our study found that red rice, especially RRCJcm red rice has the highest essential amino acid level (phenylalanine, isoleucine, valine, leucine, threonine, and histidine). The content of non-essential amino acid residues (aspartic acid, tyrosine, proline, alanine, arginine, and glycine) in RRCJcm is also richer than black rice and white rice. Therefore, it indicates that red rice has a great nutritional value for health. An essential amino acid diet is necessary to maintain physiological functions. Non-essential amino acids (glutamate, glutamine, and aspartate) play a crucial role in promoting the digestive process and protect the integrity of the intestinal mucosa [29].

\section{Profile and Total Anthocyanin Content}

The UV-Vis spectra profile shows two peaks in all red and black rice varieties, namely in the UV and visible light regions, both at $\mathrm{pH} 1.0$ and $\mathrm{pH} 4.5$ (Fig. 2(b-f)). However, in RREJbl red rice was exhibited the peak 

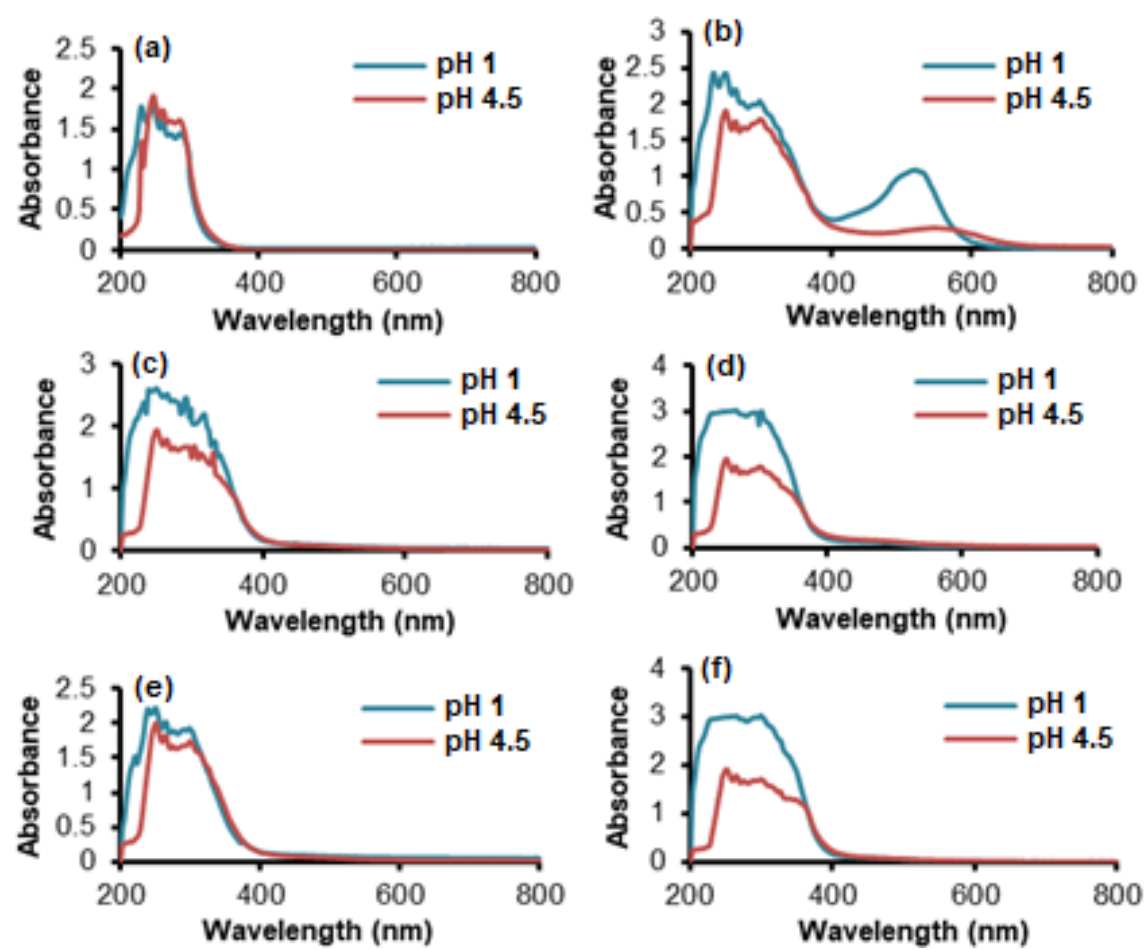

Fig 2. Anthocyanin profiles from UV-Vis spectrophotometry of (a) WREJms, (b) BREJwj, (c) RRCJcm, (d) RREJbl, (e) RRCJin and (f) RREJas

position at $451 \mathrm{~nm}$ at $\mathrm{pH} \mathrm{1,} \mathrm{while} \mathrm{at} \mathrm{pH} 4.5$, the peak position was at $466 \mathrm{~nm}$. It indicates that the absorbance shift to a longer wavelength region (bathochromic). Anthocyanins are categorized as flavonoids due to flavylium ions in the heterocyclic $\mathrm{C}$ ring. Anthocyanins are ionic; as a result, they are more stable in low $\mathrm{pH}(<3)$ solutions. At $\mathrm{pH} 4-5$, flavylium cations and quinoidal anions are moderately formed to reduce anthocyanin pigments [30]. The spectra characteristic of anthocyanins is shown by two peaks; the first peak at $240-280 \mathrm{~nm}$ is assigned as the absorption of ring $\mathrm{A}$, while the second peak at $450-560 \mathrm{~nm}$ shows the absorption of ring $B$ [31].

Red rice contains phytochemicals such as phenolics, flavonoids, leucoanthocyanidins, anthocyanidins, tannins, quinones, and anthraquinones as antioxidants properties [18]. Anthocyanins are water-soluble and most organic solvents, but they are insoluble in non-polar organic solvents. Furthermore, alkaline or neutral solutions can decrease anthocyanins' stability [30]. In this study, RREJas red rice showed the highest total anthocyanin of 10.87 $\mathrm{mg} / \mathrm{g}$ among red rice (Fig. 3). Previous research related to anthocyanins in rice showed that the total anthocyanin

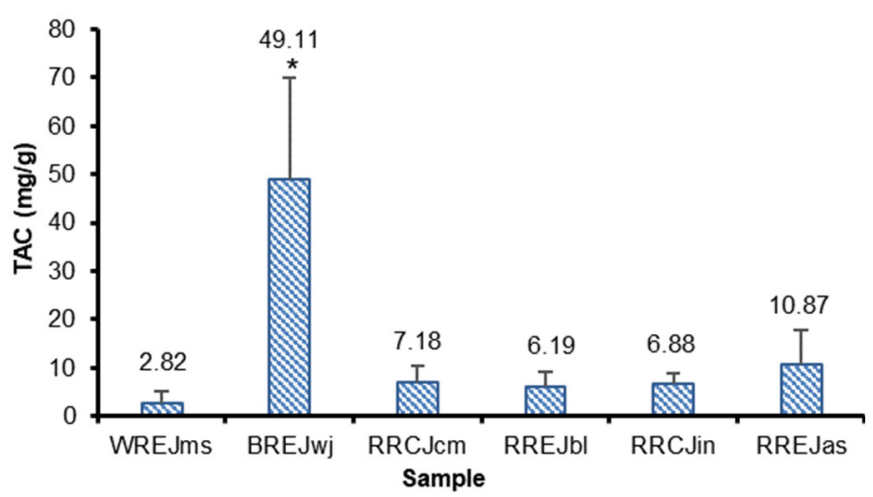

Fig 3. The total anthocyanin content (TAC) of pigmented rice. Error bars show standard deviation from triplicate. An asterisk $\left({ }^{*}\right)$ indicate the results test statistically significant $(\mathrm{p}<0.001)$

content in Sri Lanka red rice (SRI3) was $0.33 \mathrm{mg} / 100 \mathrm{~g}$ [7], whereas higher than RREJas red rice. Anthocyanins are modified by hydroxylation, methylation, glycosylation, and acylation, which control their color and stability. Modifications occurs at C3' (R1), C4' (R2), C5' (R3), C3 (R4), C5 (R5), and C7 (R6). The increase in the number of hydroxyl (-OH) groups in the B-ring will provide blue color in anthocyanins. Meanwhile, 
increased methylation generates redness in anthocyanins. B-ring methylation causes anthocyanins to be easily oxidized and destabilizes [13].

Based on the TLC analysis, two spots were found in RREJbl red rice, RREJas, and BREJwj black rice. In RRCJcm and RRCJin, one spot was found, while white rice did not show any spots in visible light. Identifying separation TLC of the bioactive compound can be quantified based on the retention factor (Rf) value. The more polar compound has a smaller $\mathrm{Rf}$ value and vice versa. Molecules with $\mathrm{OH}$ or $\mathrm{NH}_{2}$ groups are polar and more able to form hydrogen-silica matrix group ( $\mathrm{Si}-\mathrm{OH})$ bonds. Thus, the compounds are more difficult to move upwards. Simultaneously, non-polar molecules have fewer interactions with the matrix and tend to be more soluble in the eluent to move upwards faster [32].

This study showed that RREJbl and RREJas showed a similarity of Rf value. Likewise, RRCJcm and RRCJin revealed the presence of anthocyanin (Fig. 4(a)). BREJwj was assumed to contain peonidin-3-O-glucoside and pelargonidin-3-O-glucoside [33,34]. A previous study [34] stated that the separation of TLC of anthocyanin compounds in berries showed an Rf value of 0.80 , which corresponds to the pelargonidin-3-O-glucoside compound. A previous study revealed that rice bran extract's dark spots showed phenolic compounds, and blue fluorescent indicates the presence of flavonoids [12].

Characterization of flavonoids with TLC analysis of Bay leaves (Eugenia polyantha) showed the intense blue fluorescent in $366 \mathrm{~nm}$ with an $\mathrm{Rf}$ value of 0.26 indicating flavanols, and Rf of 0.44 and 0.77 represented flavones [35]. Hence, we predict that all rice may contain phenolic acid and flavonoid compounds (Fig. 4(b-c)). However, BREJwj showed the highest intensity. RREJbl red rice has a higher density than black rice and white rice (Fig. 5(a-b)). Thin-layer chromatography (TLC) analysis between black rice (O. sativa L.) from East Java, Central Java, and West Java showed that spot intensity and density were not significantly different from red rice and white rice [18].

\section{FRAP Activity of Pigmented Rice Extracts}

RREJas red rice showed the highest antioxidant activity with an $\mathrm{IC}_{50}$ value of $6.65 \mu \mathrm{g} / \mathrm{mL}$, closest to ascorbic acid with an $\mathrm{IC}_{50}$ of $5.21 \mu \mathrm{g} / \mathrm{mL}$ (Fig. 6). The smaller $\mathrm{IC}_{50}$ value shows a higher antioxidant activity. The antioxidant activities from the highest to the lowest

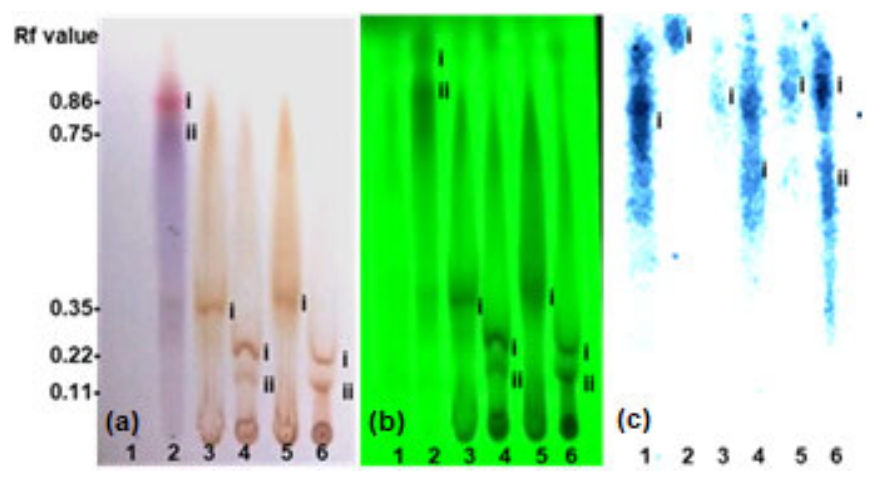

Fig 4. Anthocyanin profile based on thin layer chromatography (TLC) visualization under (a) visible light, (b) UV $254 \mathrm{~nm}$, (c) UV $366 \mathrm{~nm}$

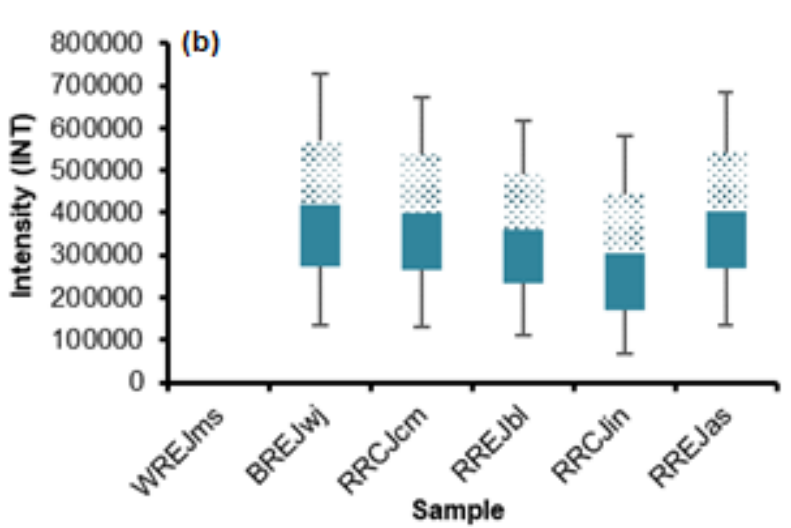

Fig 5. Density and intensity of red rice anthocyanin profiles based on TLC analysis. (a) density of each spot and (b) intensity. $1=$ WREJms. 2 = BREJwj. $3=$ RRCJcm. 4 = RREJbl. $5=$ RRCJin. $6=$ RREJas 


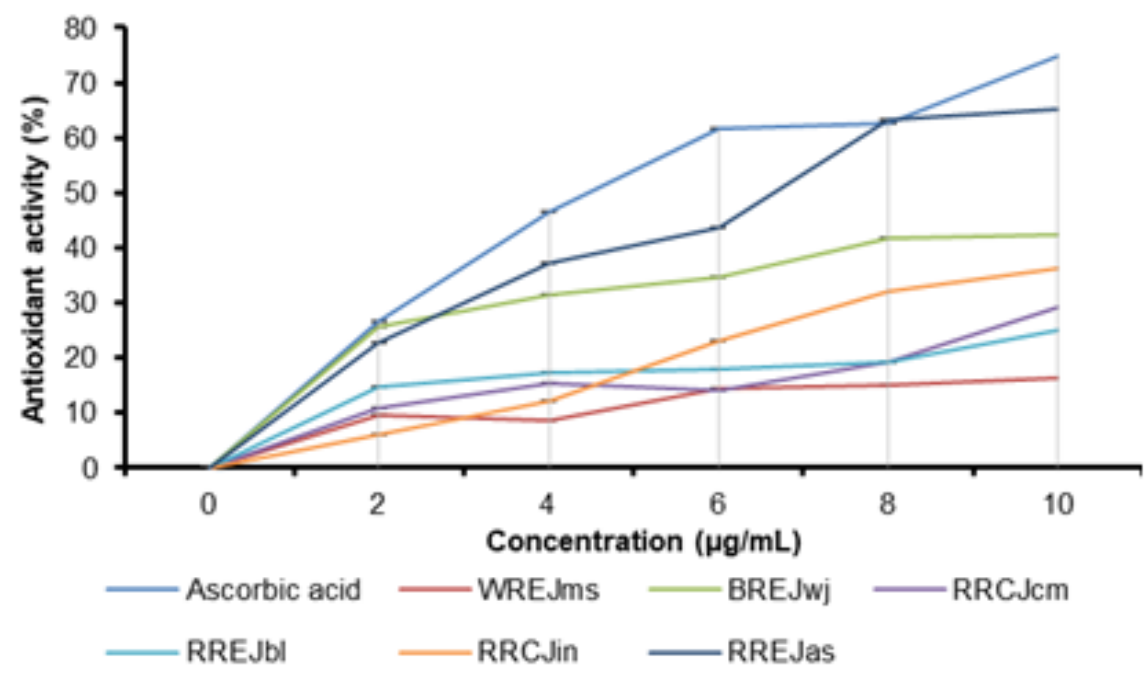

Fig 6. Antioxidant activity of pigmented rice anthocyanins in inhibiting Ferric-reducing/antioxidant power (FRAP) as free radicals. Error bars show the standard deviation from triplicates experiment

were RREJas, BREJwj, RRCJin, RRCJcm, RREJbl, and WREJms, with $\mathrm{IC}_{50}$ of $6.65,12.87,12.97,21.78,34.00$, and $43.02 \mu \mathrm{g} / \mathrm{mL}$, respectively (Table 2 ). Antioxidant activity of red rice anthocyanin extracts may have correlated with its structure, namely the number of hydroxyl groups in the pyran ring $[\mathrm{B}]$ and hydrogen donor or acceptor [16]. Furthermore, the presence of proanthocyanidin, phenolic, and flavonoid compounds is presumed to affect antioxidant activity in red rice. A previous study has shown that the antioxidant activity of red rice bran is higher than black and white rice bran in various free radical inhibition tests, which correlates positively with phenolic and flavonoid content. The dominant phenolic compounds found in red rice bran include ferulic, vanillic, and p-coumaric acids [36].

\section{Inhibition of a-Amylase Enzyme}

The $\alpha$-amylase enzyme inhibition was performed to determine the anti-diabetic activity. This study used pigmented rice extracts to assess the activity of inhibiting the $a$-amylase enzyme with the acarbose synthetic drug as a positive control. RREJas had the highest percentage of $\alpha$-amylase inhibition closes to BREJwj and acarbose with an $\mathrm{IC}_{50}$ of $144.46 \mu \mathrm{g} / \mathrm{mL}$ (Fig. 7 and Table 2). Therefore, our study indicated that RREJas red rice might have the potential as anti-diabetic. Polarity and the glucose group of anthocyanin affected to inhibit the a-amylase enzyme activity. A previous study showed that cyanidin-3-O-rutinoside is the most potent $\alpha$-amylase inhibitor between cyanidin and cyanidin-3-O-glucoside [37]. Acarbose is known as an

Table 2. $\mathrm{IC}_{50}$ value of pigmented rice anthocyanins as FRAP and $\alpha$-amylase inhibitor

\begin{tabular}{llclc}
\hline \multirow{2}{*}{ No } & \multicolumn{2}{c}{ Antioxidant activity } & \multicolumn{2}{c}{ Antidiabetic activity } \\
\cline { 2 - 5 } & Sample & $\mathrm{IC}_{50}(\mu \mathrm{g} / \mathrm{mL})$ & Sample & $\mathrm{IC}_{50}(\mu \mathrm{g} / \mathrm{mL})$ \\
\hline 1 & Ascorbic acid & 5.21 & Acarbose & 16.53 \\
2 & WREJms & 43.02 & WREJms & 198.22 \\
3 & BREJwj & 12.87 & BREJwj & 109.03 \\
4 & RRCJcm & 21.78 & RRCJcm & 172.58 \\
5 & RREJbl & 34.00 & RREJbl & 183.73 \\
6 & RRCJin & 12.97 & RRCJin & 172.20 \\
7 & RREJas & 6.65 & RREJas & 144.46 \\
\hline
\end{tabular}




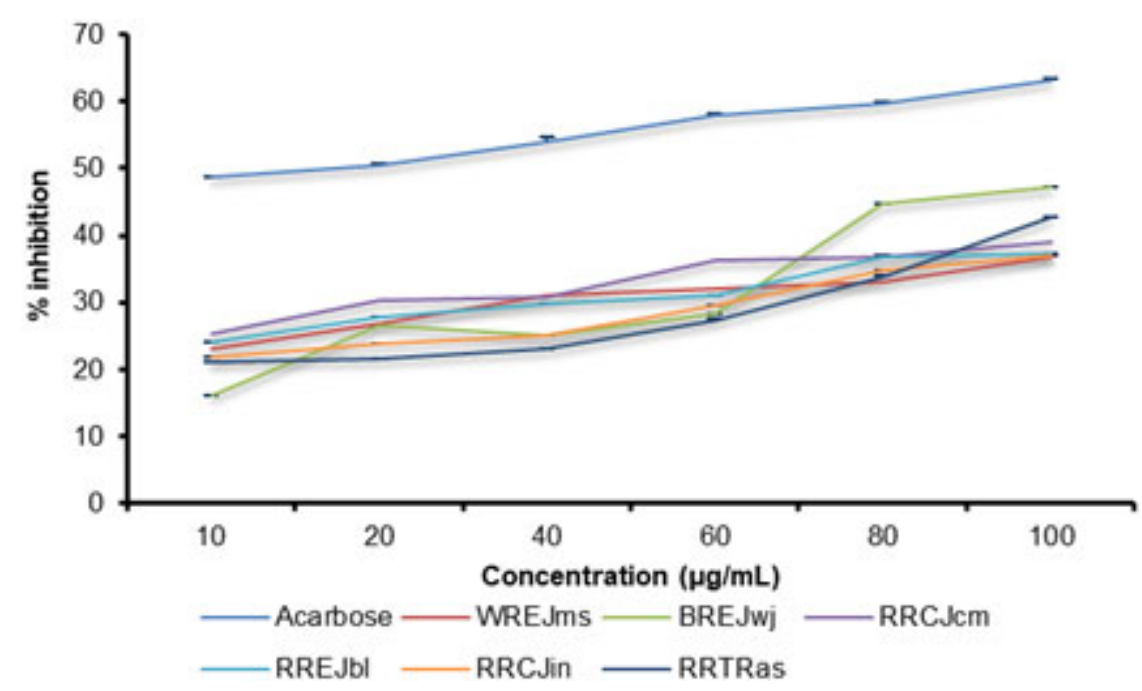

Fig 7. In vitro inhibition of $\alpha$-amylase enzyme against pigmented rice anthocyanins

anti-diabetic drug that works by inhibiting digestive enzymes. Acarbose was found to bind to the catalytic site of $\alpha$-amylase and bind to the residues of ASP197, GLU233, and ASP300. In silico studies related to anthocyanins on enzyme inhibition found that cyanidin3 -glucoside was most effective at inhibiting the $\alpha$-amylase enzyme than cyanidin-3-rutinoside, cyanidin-3.5glucoside, and peonidin-3-glucoside. However, the four anthocyanins were able to bind to the side chain of $\alpha$ amylase at the same residue as the drug acarbose, namely the residue of GLU233 [38].

\section{- CONCLUSION}

The present study revealed that carbohydrate, protein, lipid, water, and ash level in pigmented rice have different values. RREJbl red rice shows the lowest carbohydrate level. The RRCJcm red rice was rich in essential and non-essential amino acids. Thus, red rice is good for health-promoting properties. Spectra and TLC characteristics demonstrate the presence of anthocyanin in red rice. Total anthocyanin content in RREJas red rice was $10.87 \mathrm{mg} / \mathrm{g}$, higher than white rice. Moreover, RREJas had high biological function activities as antioxidant and anti-diabetic through $\alpha$-amylase inhibition. In the future, further research is needed to establish the anthocyanin compound of red rice in Indonesia by HPLC or LC/MS analysis and its health benefit.

\section{- ACKNOWLEDGMENTS}

This research is funded by Professor Grants Brawijaya University 2019-2020 No. 08/UN10.F09/PN/2020 and the DIKTI (Directorate General of Higher Education) Grant for Magister Program 2020 No. 037/SP2H/LT/DRPM/2020.

\section{- AUTHOR CONTRIBUTIONS}

Ayu Tri Agustin contributes to conception and design, acquisition of data, analysis, and interpretation of data, drafting the article, final approval of the version to be published. Anna Safitri contributes to the acquisition of data, drafting the article. Fatchiyah Fatchiyah contributes to conception and design, analysis and interpretation of data, drafting the article, critically revising the article for important intellectual content, final approval of the version to be published.

\section{- REFERENCES}

[1] Rathna Priya, T.S., Eliazer Nelson, A.R.L., Kavitha, R., and Antony, U., 2019, Nutritional and functional properties of coloured rice varieties of South India: A review, J. Ethn. Foods, 6 (1), 11.

[2] Thushara, P.A.N., Godakumbura, P.I., and Prashantha, M.A.B., 2019, Importance, health benefits and bioactivities of Sri Lankan traditional rice (Oryza sativa L.) varieties: A review, Int. J. 
Agric. Environ. Biores., 4 (3), 119-128.

[3] Wang, W., Li, Y., Dang, P., Zhao, S., Lai, D., and Zhou, L., 2018, Rice secondary metabolites: structures, roles, biosynthesis, and metabolic regulation, Molecules, 23 (12), 3098.

[4] Raghuvanshi, R.S., Dutta, A., Tewari, G., and Suri, S., 2017, Qualitative characteristics of red rice and white rice procured from local market of Uttarakhand: A comparative study, J. Rice Res., 10 (1), 49-53.

[5] Saragih, B., Naibaho, N.M., and Saragih, B., 2019, Nutritional, functional properties, glycemic index and glycemic load of indigenous rice from North and East Borneo, Food Res., 3 (5), 537-545.

[6] Ghasemzadeh, A., Karbalaii, M.T., Jaafar, H.Z.E., and Rahmat, A., 2018, Phytochemical constituents, antioxidant activity, and antiproliferative properties of black, red, and brown rice bran, Chem. Cent. J., 12 (1), 17.

[7] Sompong, R., Siebenhandl-Ehn, S., LinsbergerMartin, G., and Berghofer, E., 2011, Physicochemical and antioxidative properties of red and black rice varieties from Thailand, China and Sri Lanka, Food Chem., 124 (1), 132-140.

[8] Thitipramote, N., Pradmeeteekul, P., Nimkamnerd, J., Chaiwut, P., Pintathong, P., and Thitilerdecha, N., 2016, Bioactive compounds and antioxidant activities of red (Brown Red Jasmine) and black (Kam Leum Pua) native pigmented rice, Int. Food Res. J., 23 (1), 410-414.

[9] Anggraeni, V.J., Ramdanawati, L., and Ayuantika, W., 2019, Optimization of total anthocyanin extraction from brown rice (Oryza nivara), J. Phys.: Conf. Ser., 1338, 012006.

[10] Wahyuningsih, S., Wulandari, L., Wartono, M.W., Munawaroh, H., and Ramelan, A.H., 2017, The effect of $\mathrm{pH}$ and color stability of anthocyanin on food colorant, IOP Conf. Ser.: Mater. Sci. Eng., 193, 012047.

[11] Dyankova, S., and Doneva, M., 2016, Extraction and characterization of anthocyanin colorants from plant sources, AST, 8 (1), 85-89.

[12] Rukmana, R.M., Soesilo, N.P., Rumiyati, R., and Pratiwi, R., 2017, The effect of ethanolic extract of black and white rice bran (Oryza sativa L.) on cancer cells, Indones. J. Biotechnol., 21 (1), 63-69.
[13] Wu, H.Y., Yang, K.M., and Chiang, P.Y., 2018, Roselle anthocyanins: antioxidant properties and stability to heat and pH, Molecules, 23 (6), 1357.

[14] Ali, H.M., Almagribi, W., and Al-Rashidi, M.N., 2016, Antiradical and reductant activities of anthocyanidins and anthocyanins, structureactivity relationship and synthesis, Food Chem., 194, 1275-1282.

[15] Agustin, A.T., Safitri, A., and Fatchiyah, F., 2020, An in silico approach reveals the potential function of cyanidin-3-O-glucoside of red rice in inhibiting the advanced glycation end products (AGES)receptor (RAGE) signaling pathway, Acta Inform. Med., 28 (3), 170-179.

[16] Sari, D.R.T., Cairns, J.R.K., Safitri, A., and Fatchiyah, F., 2019, Virtual prediction of the delphinidin-3-O-glucoside and peonidin-3-Oglucoside as anti-inflammatory of TNF- $\alpha$ signaling, Acta Inform. Med., 27 (3), 152-157.

[17] Rahayu, W.M., Astuti, M., and Marsono, Y., 2019, Improved hypoglycemic effect of anthocyanin extract combination from red rice and black soybean, J. Phys.: Conf. Ser., 1146, 012015.

[18] Fatchiyah, F., Sari, D.R.T., Safitri, A., and Cairns, J.R.K., 2020, Phytochemical compound and nutritional value in black rice from Java Island, Indonesia, Syst. Rev. Pharm., 11 (7), 414-421.

[19] Boue, S.M., Daigle, K.W., Chen, M.H., Cao, H., and Heiman, M.L., 2016, Antidiabetic potential of purple and red rice (Oryza sativa L.) bran extracts, J. Agric. Food Chem., 64 (26), 5345-5353.

[20] Khalil-Moghaddam, S., Ebrahim-Habibi, A., Pasalar, P., Yaghmaei, P., and Hayati-Roodbari, N., 2012, Reflection on design and testing of pancreatic alpha-amylase inhibitors: An in silico comparison between rat and rabbit enzyme models, Daru, J. Pharm. Sci., 20 (1), 77.

[21] Cirak, C., and Radusiene, J., 2019, Factors affecting the variation of bioactive compounds in Hypericum species, Biol. Futura, 70 (3), 198-209.

[22] Sadimantara, M.S.A., Asranudin, Holilah, Sadimantara, F.N., and Asyik, N., 2019, Physicochemical and antioxidant properties of red 
rice varieties of Wakawondu and Wangkariri from North Buton, Indonesia, Int. J. Sci. Technol. Res., 8 (8), 1623-1627.

[23] Kurnianingsih, N., Ratnawati, R., Fatchiyah, F., Barlianto, W., Ali, M.M., Safitri, A., and Suyanto, E., 2019, The difference of amino acid profiling from two morphological purple sweet potatoes from Kawi Mountain cultivars, East Java, Indonesia, J. Phys.: Conf. Ser., 1374, 012017.

[24] Dini, C., Zaro, M.J., Rolny, N., Caputo, M., Boido, E., Dellacassa, E., and Viña, S.Z., 2020, Characterization and stability analysis of anthocyanins from Pachyrhizus ahipa (Wedd) Parodi roots, Food Biosci., 34, 100534.

[25] Laokuldilok, T., Shoemaker, C.F., Jongkaewwattana, S., and Tulyathan, V., 2011, Antioxidants and antioxidant activity of several pigmented rice brans, J. Agric. Food Chem., 59 (1), 193-199.

[26] Kazeem, M.I., Ogunbiyi, J.V., and Ashafa, A.O.T., 2013, In vitro studies on the inhibition of a-amylase and $\alpha$-glucosidase by leaf extracts of Picralima nitida (Stapf), Trop. J. Pharm. Res., 12 (5), 719-725.

[27] Thaidi, N.I.A., Jusoh, H.M., Ghazali, A.B., Susanti, D., and Haron, N., 2020, The effect of bioactive polyphenols from Anacardium occidentale Linn. leaves on $\alpha$-amylase and dipeptidyl peptidase IV activities, Indones. J. Chem., 20 (5), 1010-1017.

[28] Kulasinghe, A., Samarasinghe, G., Wimalasiri, S., Silva, R., and Madhujith, T., 2019, Macronutrient and Mineral Composition of Selected Traditional Rice Varieties in Sri Lanka, Proceedings of the International Conference on Food Quality, Safety and Security (FOOD QualSS 2018), Colombo, Sri Lanka, 24-25 October 2018.

[29] Wu, G., 2014, Dietary requirements of synthesizable amino acids by animals: A paradigm shift in protein nutrition, J. Anim. Sci. Biotechnol., 5 (1), 34.

[30] Khoo, H.E., Azlan, A., Tang, S.T., and Lim, S.M., 2017, Anthocyanidins and anthocyanins: colored pigments as food, pharmaceutical ingredients, and the potential health benefits, Food Nutr. Res., 61 (1), 1361779.

[31] Kumar, S., and Pandey, A.K., 2013, Chemistry and biological activities of flavonoids: An overview, Sci. World J., 2013, 162750.

[32] Namir, H., Hadžić, R., Malešević, I., Jurčević, M., and Starčević, D., 2019, Application of thin layer chromatography for qualitative analysis of gunpowder in purpose of life prediction of ammunition, Int. J. Biosens. Bioelectron., 5 (1), 4-12.

[33] Cretu, G.C., and Morlock, G.E., 2014, Analysis of anthocyanins in powdered berry extracts by planar chromatography linked with bioassay and mass spectrometry, Food Chem., 146, 104-112.

[34] Filip, M., Vlassa, M., Copaciu, F., and Coman, V., 2012, Identification of anthocyanins and anthocyanidins from berry fruits by chromatographic and spectroscopic techniques to establish the juice authenticity from market, JPC J. Planar Chromatogr. - Mod. TLC, 25 (6), 534-541.

[35] Syarifah, A.L., Retnowati, R., and Soebiantoro, S., 2019, Characterization of secondary metabolites profile of flavonoid from salam leaves (Eugenia polyantha) using TLC and UV spectrophotometry, Pharm. Sci. Res., 6 (3), 155-163.

[36] Jun, H.I., Song, G.S., Yang, E.I., Youn, Y., and Kim, Y.S., 2012, Antioxidant activities and phenolic compounds of pigmented rice bran extracts, J. Food Sci., 77 (7), C759-C764.

[37] Akkarachiyasit, S., Yibchok-Anun, S., Wacharasindhu, S., and Adisakwattana, S., 2011, In vitro inhibitory effects of cyandin-3-rutinoside on pancreatic $\alpha$-amylase and its combined effect with acarbose, Molecules, 16 (3), 2075-2083.

[38] Sui, X., Zhang, Y., and Zhou, W., 2016, In vitro and in silico studies of the inhibition activity of anthocyanins against porcine pancreatic $\alpha$-amylase, J. Funct. Foods, 21, 50-57. 